\title{
Canonical TGF- $\beta$ Signaling Is Required for the Balance of Excitatory/Inhibitory Transmission within the Hippocampus and Prepulse Inhibition of Acoustic Startle
}

\author{
Mu Sun, ${ }^{1,2}$ Jonathan C. Gewirtz, ${ }^{3}$ Lisa Bofenkamp, ${ }^{1,2}$ Robert J. Wickham, ${ }^{3}$ Hong Ge, ${ }^{1}$ and Michael B. 0'Connor ${ }^{1,2}$ \\ ${ }^{1}$ Department of Genetics, Cell Biology and Development, ${ }^{2}$ Howard Hughes Medical Institute, and ${ }^{3}$ Departments of Psychology and Neuroscience, University \\ of Minnesota, Minnesota 55455
}

\begin{abstract}
Smad4 is a unique nuclear transducer for all TGF- $\beta$ signaling pathways and regulates gene transcription during development and tissue homeostasis. To elucidate the postnatal role of TGF- $\beta$ signaling in the mammalian brain, we generated forebrain-specific Smad 4 knockout mice. Surprisingly, the mutants showed no alteration in long-term potentiation and water maze, suggesting that Smad4 is not required for spatial learning and memory. However, these mutant mice did show enhancement of paired-pulse facilitation in excitatory synaptic transmission and stronger paired-pulse depression of $\mathrm{GABA}_{\mathrm{A}}$ currents in the hippocampus. The alteration of hippocampal electrophysiology correlated with mouse hyperactivity in homecage and open field tests. Mutant mice also showed overgrooming as well as deficits of prepulse inhibition, a widely used endophenotype of schizophrenia. With a specific real-time PCR array focused on TGF- $\beta$ signaling pathway, we identified a novel regulation mechanism of the pathway in the hippocampal neurons, in which Smad4-mediated signaling suppresses the level of extracellular antagonism of TGF- $\beta$ ligands through transcriptional regulation of follistatin, a selective inhibitor to activin/TGF- $\beta$ signaling in the hippocampus. In summary, we suggest that the canonical TGF- $\beta$ signaling pathway is critical for use-dependent modulation of $\mathrm{GABA}_{\mathrm{A}}$ synaptic transmission and dendritic homeostasis; furthermore, a disruption in the balance of the excitatory and inhibitory hippocampal network can result in psychiatric-like behavior.
\end{abstract}

\section{Introduction}

The evolutionarily conserved TGF- $\beta$ superfamily (transforming growth factor $\beta$ ) includes two major subfamilies: the TGF- $\beta$ s/ activins and the bone morphogenetic proteins (BMPs). TGF- $\beta$ family members bind to and activate transmembrane serine/ threonine receptors (Massagué, 1996). During canonical signaling, type I receptors phosphorylate receptor-activated Samds (R-Smad), which then associate with Smad4, the common Smad (Co-Smad). The Smad complex accumulates in the nucleus, in which it modulates transcription of target genes. Signaling through the canonical pathway is involved in multiple aspects of neurodevelopment (Liu and Niswander, 2005), adult neurogenesis (Ageta et al., 2008; Colak et al., 2008) and neuroprotection (König et al., 2005). There is also evidence that TGF- $\beta$ signaling contributes to neurodegeneration in Alzheimer's disease (Tesseur et al., 2006; Ueberham et al., 2006) and altered cognitive abilities (Loeys et al., 2005). In addition, it has been found that components of TGF- $\beta$ signaling pathway are altered in the hippocampus in human psychiatric conditions

\section{Received Feb. 12, 2010; accepted March 10, 2010}

We thank Dr. loannis Dragatsis of the University of Tennessee for sending us CaMKII-Cre mice, Dr. Chu-Xia Deng of the National Institutes of Health for gift of Smad4 floxed mice, and Dr. Aidan Peterson for comments on this manuscript.

Correspondence should be addressed to Michael B. O'Connor, Department of Genetics, Cell Biology and Development, Howard Hughes Medical Institute, University of Minnesota, 6-160 Jackson Hall, 321 Church Street Southeast, Minneapolis, MN 55455. E-mail: moconnor@umn.edu.

DOI:10.1523/JNEUROSCI.0789-10.2010

Copyright $\odot 2010$ the authors $\quad 0270-6474 / 10 / 306025-11 \$ 15.00 / 0$ such as schizophrenia and bipolar disorder (Benes et al., 2007), and manipulation of TGF- $\beta$ signaling has been proposed as a possible treatment for anxiety and depression (Dow et al., 2005; Ageta et al., 2008; Zheng et al., 2009).

Cooperating with the canonical pathway in mediating neuronal development and plasticity, noncanonical pathways that signal through MAP kinase (Chin et al., 2002) and LIM kinase (Lee-Hoeflich et al., 2004; Eaton and Davis, 2005) have been identified as initiating parallel signaling events. However, it is not known how canonical and noncanonical pathways coordinate to elicit the proper physiological responses.

In Drosophila, activin signaling is critical for axon guidance (Parker et al., 2006; Serpe and O'Connor, 2006; Zheng et al., 2006) and remodeling (Zheng et al., 2003), while signaling by BMP family members regulates synaptic growth (McCabe et al., 2004), stability (Eaton and Davis, 2005), and homeostasis (Goold and Davis, 2007). TGF- $\beta$ signaling also regulates synaptic transmission and plasticity in multiple circuits in different organisms including glutamergic transmission at the Drosophila neural muscular junction (McCabe et al., 2004), cholinergic transmission between motoneurons and interneurons in the CNS of Drosophila (Baines, 2004), glutamergic transmission between sensory and motor neurons in Aplysia ganglia (Zhang et al., 1997), and modulation of hippocampal network in mammals (Fukushima et al., 2007; Sun et al., 2007; Zheng et al., 2009).

As a first step in discriminating the canonical and noncanonical TGF- $\beta$ pathways in regulating hippocampal plasticity and related behavior in mammals, we focused on Smad4, the unique 
canonical signal transducer common to both TGF- $\beta$ /activin and BMP signaling pathways. Since Smad4 is essential for normal mouse development, we generated forebrain-specific conditional Smad4 knockout $(\mathrm{KO})$ mice and systematically characterized the phenotypes of mutant mice in vitro and in vivo. We identified a role for canonical TGF- $\beta$ signaling in regulating shortterm plasticity in CA1 of the hippocampus as well as hyperactivity in mutants. We also revealed a novel regulation of the TGF- $\beta$ signaling pathway in the hippocampal neurons, in which Smad4-mediated signaling controls the potency of extracellular antagonism of TGF- $\beta$ ligands through transcriptional regulation of follistatin, an inhibitor of activin and BMP ligands.

\section{Materials and Methods}

\section{Conditional knock-out mice}

Smad 4 conditional knock-out mice were generated following a standard breeding strategy (Law et al., 2003). Congenic Smad4 $4{ }^{\mathrm{f} / \mathrm{f}}, \mathrm{CreH}^{+}(\mathrm{Smad} 4$ $\mathrm{KO}$ ), and $\mathrm{Smad} 4^{\mathrm{f} / \mathrm{f}}, \mathrm{CreH}^{-}$(control) mice in C57BL/6J background (at least five backcrosses) were produced by crossing floxed Smad4 mice (Yang et al., 2002) with a hippocampus-restricted Cre transgenic line (R1Ag5, Cre-CaMKII, $\mathrm{CreH}^{+}$) (Dragatsis and Zeitlin, 2000). Two- to three-month-old male mice were used in this study, following protocols approved by the Institutional Animal Care and Use Committee at the University of Minnesota.
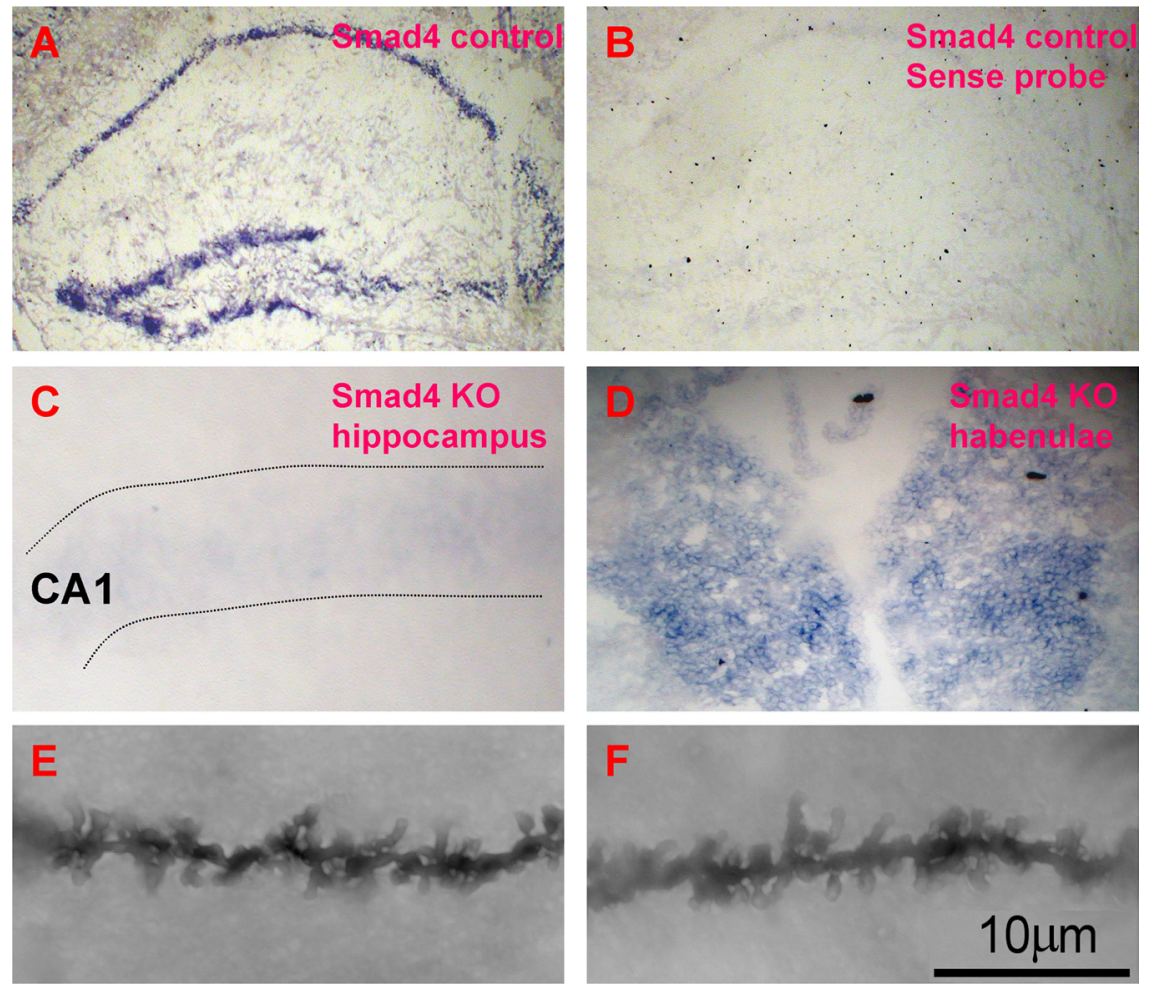

Figure 1. Conditional deletion of Smad4 in mouse hippocampus and normal spine density in CA1 of Smad4 mutants. $\boldsymbol{A}-\boldsymbol{D}$ Confirmation of deletion of Smad4 in adult mouse hippocampus by in situ hybridization. $\boldsymbol{A}$, Smad $4 \mathrm{mRNA}$ is detected in 3-monthold control mouse hippocampus by antisense probe. $\boldsymbol{B}$, With sense control probe, Smad4 could not be detected in the wild-type adult brain. C, Under higher magnification, Smad4 could not be detected from CA1 of Smad4 K0 mice. D, Smad4 was still highly expressed in the habenulae of the same section. $\boldsymbol{E}, \boldsymbol{F}$, Golgi staining showed apical tertiary dendrites of CA1 pyramidal neurons from Smad4 KO and control mice. Scale bar (in F): $\boldsymbol{A}, \boldsymbol{B}, 100 \mu \mathrm{m} ; \boldsymbol{C}, \boldsymbol{D}, 25 \mu \mathrm{m} ; \boldsymbol{E}, \boldsymbol{F}, 10 \mu \mathrm{m}$.

\section{Statistics and data analysis}

Unpaired $t$ tests were used for mutants and control littermates for in vitro or in vivo experiments, with a type I error rate of $\alpha=0.05$ (two-tailed). All experimental data are expressed as mean \pm SEM.

\section{In situ hybridization}

Smad4 sense and antisense cRNA probes were labeled with digoxigenin (DIG) using the DIG RNA Labeling Mix (Roche Diagnostics). Twentymicrometer cryostat mouse brain sections were postfixed in $4 \%$ paraformaldehyde at room temperature for $15 \mathrm{~min}$ and hybridized with the DIG-labeled probes at $70^{\circ} \mathrm{C}$ overnight. After extensive washing, alkaline phosphatase-coupled anti-DIG Fab fragment antibody (1:5000; Roche Diagnostics) were applied at $4^{\circ} \mathrm{C}$ overnight. The hybridization signals were detected using an alkaline phosphatase reaction with nitroblue tetrazolium and 5-bromo-4-chloro-3-indolyl phosphate as substrates and observed with light microscopy.

\section{Golgi staining}

Brain tissue treatment followed the user manual for the FD Rapid GolgiStain Kit. One hundred-micrometer cryosections were stained and observed under a $100 \times$ oil objective. The tertiary dendrites $(>20 \mu \mathrm{m}$ segments) in the stratum radiatum were traced. A serial set of pictures, encompassing all spines on the dendrite, were taken and $Z$ projected at maximal intensity in NIH ImageJ software (Sun et al., 2007).

\section{Preparation of hippocampal slices and}

electrophysiological recordings

Mice were decapitated after halothane anesthesia, and hippocampal slices (350 $\mu \mathrm{m}$ thick) were cut in ice-cold artificial CSF (ACSF) containing the following (in $\mathrm{mM}$ ): 250 sucrose, $25 \mathrm{NaHCO}_{3}, 25$ glucose, $2.5 \mathrm{KCl}$, $1.25 \mathrm{NaH}_{2} \mathrm{PO}_{4}, 2 \mathrm{CaCl}_{2}$, and $1.5 \mathrm{MgCl}_{2}$ (pH 7.3, $320 \mathrm{mOsm}$ ). The slices recovered in a submerged chamber at $32^{\circ} \mathrm{C}$ for $20 \mathrm{~min}$ and then incubated at room temperature $\left(24-25^{\circ} \mathrm{C}\right)$ in carbogen-bubbled ACSF, con- taining $125 \mathrm{~mm} \mathrm{NaCl}$ in place of $250 \mathrm{~mm}$ sucrose, for at least $2 \mathrm{~h}$ before the start of recordings. Field EPSP recordings and long-term potentiation (LTP) induction protocols were performed according to previously published procedures (Sun et al., 2007).

\section{Isolation of IPSCs and recording of paired-pulse depression}

Pyramidal neurons in CA1 were identified by IR-DIC microscope (Zeiss Axioskop 2 FS plus) in a submerged recording chamber $\left(30^{\circ} \mathrm{C}\right)$. Data were acquired by EPC10 Double (HEKA) and PatchMaster (HEKA) software. Patch electrodes ( $3-5 \mathrm{M} \Omega$ ) contained the following (in $\mathrm{mM}$ ): 117 potassium gluconate, $2.8 \mathrm{NaCl}, 20 \mathrm{HEPES}, 0.4$ EGTA, 5 TEA-Cl, 2.5 MgATP, and 0.25 MgGTP, pH 7.2-7.4 (285-295 mOsm). For IPSC recordings, the intracellular $\left[\mathrm{Cl}^{-}\right]$was elevated by a change of $60 \mathrm{KCl}$ and $85 \mathrm{~mm}$ potassium gluconate, thus increasing the driving force of $\mathrm{GABA}_{\mathrm{A}}$ receptor-mediated chloride currents. Miniature EPSCs of pyramidal neurons were recorded with $20 \mu \mathrm{m}$ bicuculline. Miniature and evoked IPSCs were isolated by application of AMPA and NMDA receptor antagonists, CNQX $(25 \mu \mathrm{M})$ and AP-5 (50 $\mu \mathrm{M}$, Tocris Bioscience), respectively. Paired-pulse depression (PPD) was examined at 25, 50, 100, and $200 \mathrm{~ms}$ interstimulus intervals (ISIs) with stimulation strength correlated to $30 \%$ of the maximal evoked IPSC. Both miniature EPSCs and miniature IPSCs of pyramidal neurons were recorded using voltage clamp at $-60 \mathrm{mV}$ with $1 \mu \mathrm{M}$ TTX and were detected by Mini Analysis Program (Synaptosoft) from continuous recordings of $3 \mathrm{~min}$. To avoid effects of presynaptic $\mathrm{GABA}_{\mathrm{B}}$ receptors, the $\mathrm{GABA}_{\mathrm{B}}$ receptor antagonist CGP54626 (200 nM) was bath applied during these experiments. Serial resistance in the wholecell configuration is $\sim 25-30 \mathrm{M} \Omega$. Cells were discarded when either input or serial resistance changed $>25 \%$ after baseline recording.

\section{Behavioral assays}

Open field. Animal behaviors were videotaped and analyzed by both realtime and off-line versions of the Topscan system (Clever System). Mice were put into one of four test cages $(50 \times 50 \times 40 \mathrm{~cm})$ with a novel object 

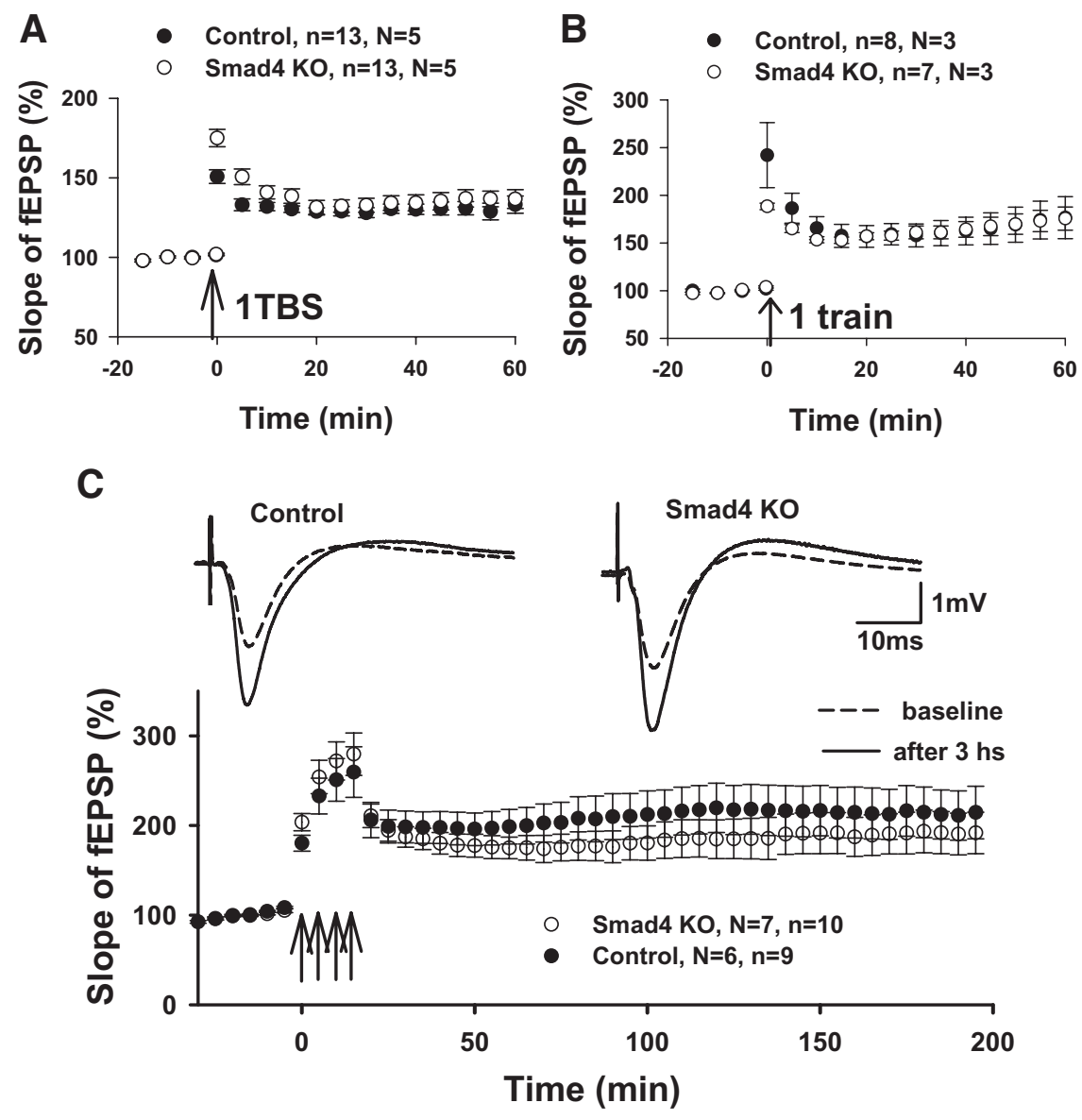

Figure 2. Normal LTP in CA1 of $S$ mad4 mutants with different protocols and configuration. $\boldsymbol{A}$, In a submerged recording chamber, one train of TBS induced similar levels of LTP from two groups. Mean amplitudes of fEPSPs recorded $0-20$ min before induction of LTP were set as a baseline. $B, A$ single train of $100 \mathrm{~Hz}$ protocol induced a similar level of LTP in Smad4 $\mathrm{K} 0$ and control slices from interface chamber. $C, A$ train of $100 \mathrm{~Hz}$ in $1 \mathrm{~s}$ given four times with 5 min interval induces late-phase LTP at the same level in both Smad4 $\mathrm{KO}$ and control slices. Averaged sweeps of baseline and $3 \mathrm{~h}$ after induction are shown above the accumulated plot.

(5 $\mathrm{cm}$ diameter bottle cap) located $12.5 \mathrm{~cm}$ from the wall. Mice were allowed to explore the cages for $15 \mathrm{~min}$ and their movements were recorded.

$Y$-maze. The Y-maze includes three identical arms $(36 \mathrm{~cm}$ long, 12.5 $\mathrm{cm}$ high, $7.5 \mathrm{~cm}$ wide, made of transparent Plexiglas) and a $7.5 \mathrm{~cm}$ hexagon as the hub in the center of the maze. Visual cues were put on the wall of testing room to enable the animal to locate itself spatially. During the acquisition trial, one arm was blocked. A mouse was placed into the hub and allowed to freely explore the two open arms and the hub for $15 \mathrm{~min}$. Three hours later, the mouse was placed in the maze with all arms open for $5 \mathrm{~min}$ (recall trial). The novel arm stay was calculated from stay of novel arm divided by total arm stay (Sun et al., 2007).

Water maze. Water maze analysis was performed in a 1.2-m-diameter opaque pool (Sun et al., 2007). Briefly, mice were trained to locate a submerged $10 \mathrm{~cm}$ platform $(0.5 \mathrm{~cm}$ under the water $)$ in an arbitrary quadrant of the pool during $90 \mathrm{~s}$ training trials. Two trials per day were given at the same time of each training day, with a 30 min interval between trials. On the first day of the experiment (day 0 ), an individual mouse was put on the platform with a visible cue (a $15 \mathrm{~cm} \mathrm{flag}$ ) for $15 \mathrm{~s}$ as a primer. During the probe trial, mice swam $60 \mathrm{~s}$ without a platform and the length of stay in each quadrant was analyzed. After the first probe test, the platform was put in a new position and then mice were trained for another $4 \mathrm{~d}$ (reversal test).

Elevated plus maze. The elevated plus maze test followed previously published protocols (Law et al., 2003) with a slight modification. The apparatus consists of two opposing open arms $(36.5 \times 7.5 \mathrm{~cm})$ and two opposing closed arms (same size of the open arms but with $12.5 \mathrm{~cm}$ high walls) extending from a central square platform $(12 \times 12 \mathrm{~cm})$. The apparatus was elevated $75 \mathrm{~cm}$ above the floor. Curtains were hung around the maze to block spatial cues in the test room. Animals were placed in the center of the maze facing one open arm and returned to their home cage after $5 \mathrm{~min}$. The following parameters were analyzed with the software: number of entries into the arms (body center in the arm); duration and speed on open arms and closed arms; risk assessment of the open arms from the protected area (the mouse body in the center and closed arms, its nose in the open arms); head dip, which is defined as nose out of the edge of the open arms.

\section{Homecage behavior}

Male mice were imported to the behavior testing room at least $3 \mathrm{~d}$ before the experiment. Each male mouse was housed in a standard small specific-pathogen-free box with ad libitum access to food and drink $1 \mathrm{~d}$ before video acquisition. Each experiment includes four cages that face four digital video cameras (JVC, GR-D270). The light cycle was set to 8 A.M.- 8 P.M. normal light and 8 P.M.-8 A.M. red light. Video was acquired by HomeCageScan software (Clever System) and stored to a Dell computer with 500GB hard drive for off-line analysis. For estimation of the accuracy of computer scoring, we reviewed 100 instances of each behavior for a single C57BL/6 mouse, unless the behavior occurred $<100$ times during the $24 \mathrm{~h}$ test video, giving an accuracy percentage for each behavior.

\section{The acoustic startle reflex and habituation of startle}

The acoustic startle reflex was measured using four identical ventilated, sound-attenuated acoustic chambers $(51 \mathrm{~cm} \times 55 \mathrm{~cm} \times 31 \mathrm{~cm}$; Med Associates), each equipped with two speakers, a mouse holder, and a transducer system through which the startle responses were recorded. Chambers were connected to an amplifier and to a computer equipped with the Advanced Startle software (MED Associates). Test sessions were preceded by a 5 min acclimation period in the startle chambers during which a 65 $\mathrm{dB}$ background noise were continuously present. Mice were given 54 trials in nine blocks of 6 trials each. Each six-trial block contained one startle stimulus trial (a $40 \mathrm{~ms}, 120 \mathrm{~dB}$ pulse of white noise), one null trial (no stimulus) and four prepulse trials (20 ms bursts of 68, 71, 77, and 82 $\mathrm{dB}$ white noise, followed $100 \mathrm{~ms}$ later by the startle pulse).

PPI was calculated using the following equation:

$$
\% \text { PPI }=100
$$

$$
\times[(\text { pulse-alone })-(\text { prepulse }+ \text { pulsescore })] / \text { pulse-alone score } \text {. }
$$

\section{Real-time PCR}

Total RNAs were extracted from the CA1 region of the hippocampus with TRIzol reagent (Invitrogen) and purified using RNeasy (Qiagen). Each RNA was treated with DNase I to remove genomic DNA. Firststrand cDNAs were synthesized from total RNAs $(2 \mu \mathrm{g})$ using ThermoScript RT-PCR system (Invitrogen) with oligo(dT) 20 primer in a total reaction mixture of $20 \mu$ l. Each reaction was diluted with distilled water to a final volume of $50 \mu \mathrm{l}$ and $1 \mu \mathrm{l}$ of the cDNA pool was subject to qPCR analysis with primer pairs designed with PerlPrimer (http://perlprimer. sourceforge.net). Q-PCR was performed by Eppendorf Realplex using RT2 real-time SYBR green PCR master mix (SuperArray) in a final vol- 
ume of $25 \mu$ l. PCR conditions were $95^{\circ} \mathrm{C}$ for $10 \mathrm{~min}$ : 1 cycle, followed by $95^{\circ} \mathrm{C}$ for $30 \mathrm{~s}, 58^{\circ} \mathrm{C}$ for $30 \mathrm{~s}$, and $72^{\circ} \mathrm{C}$ for $30 \mathrm{~s}: 40-45$ cycles. The transcriptional levels were normalized with cyclophilin A transcriptional levels in the same samples. The expression level of control CA1 or cerebellum was calibrated as 1 . Triplicate measures of each sample were conducted to ensure the consistency of the amplification. TGF- $\beta$ pathway PCR arrays (PAMM-035) were performed following the user manual and data were analyzed with SABiosciences online software.

\section{Western blotting}

Total proteins from hippocampi or cerebella were separated on NuPAGE 4-12\% Bis-Tris gel and stained with primary antibodies overnight. Smad4 (Santa Cruz, 1:100), H3 (Millipore, 1:100), Cre (Novagen, 1:5000), follistatin (Abnova, 1:500), glyceraldehyde 3-phosphate dehydrogenase (GAPDH) (Ambion, 1:5000), phospho-Smad1/5/8 (1:250 Cell Signaling Technology), and phospho-Smad2 (1:1000, Cell Signaling Technology). For simultaneous multiple detection of target proteins, IRDye 700 or 800 secondary antibodies were used at 1:5000 dilution and the blots were scanned and quantified with Odyssey Infrared Imaging System (Li-Cor Biosciences).

\section{Results}

Conditional deletion of Smad4 in the mouse forebrain did not alter long-term potentiation in CA1 or spatial learning

Previously, we demonstrated that loss of chordin, a potent BMP inhibitor, leads to enhanced CA1 LTP and spatial learning suggesting a role for BMP signaling in regulating hippocampal activity (Sun et al., 2007). Likewise, activin was found to tune GABAergic transmission and anxiety behavior (Zheng et al., 2009). To further investigate the postnatal role of canonical TGF- $\beta$ signaling in the hippocampus, we crossed floxed Smad4 mice (Yang et al., 2002) with a strong hippocampal-expressing Cre transgenic line (R1Ag5, Cre-CaMKII) (Dragatsis and Zeitlin, 2000) to generate spatial and temporal deletion of Smad4 in adult mouse forebrain ( $\mathrm{Smad} 4{ }^{\mathrm{f} / \mathrm{f}}, \mathrm{CreH}^{+}$, abbreviated as $\left.\mathrm{KO}\right)$. An in situ hybridization experiment demonstrated mRNA of Smad4 can be detected in the adult control mouse brain $\left(\operatorname{Smad} 4{ }^{\mathrm{f} / \mathrm{f}}\right.$, $\mathrm{CreH}^{-}$, abbreviated as control), especially in the hippocampus (Fig. 1A,B), in which multimodal information is integrated and processed. The Cre transgene appeared to be highly active in the forebrain area of 3-month-old $\mathrm{KO}$ mice since we detected little Smad4 mRNA in hippocampi (Fig. 1C; supplemental Fig. 1, available at www.jneurosci.org as supplemental material), but were still able to detect high level of Smad 4 mRNA in adjacent habenulae (Fig. 1D), a region that does not express Cre. Quantitative PCR and Western blotting also verified spatial deletion of mRNA and protein of Smad4 in adult hippocampus, but not in other brain areas, such as the cerebellum (supplemental Fig. 1, available at www.jneurosci.org as supplemental material). These data confirmed that we were able to successfully delete Smad4 in the postnatal hippocampus. Morphological assays show grossly normal hippocampal structure (hematoxylin and eosin staining, data not shown) and Golgi staining revealed no significant differences in spine density on tertiary dendrites of pyramidal neurons from Smad4 KO and control mice (13.64 $\pm 0.48, n=22$ vs $12.82 \pm 0.37 / 10 \mu \mathrm{m}, n=31$ from two pairs of Smad4 KO and control mice, $p=0.18$ ) (Fig. $1 E, F)$.

Consistent with results from previous pan-neuronal deletion of Smad4 (Zhou et al., 2003), we found no significant difference in hippocampal long-term synaptic plasticity between Smad4 KO mice and control mice. Smad4 KO mice showed both normal early-phase LTP and late-phase LTP in the CA1 region of hippocampus (Fig. 2). With a submerged chamber, one train of theta burst stimulation (TBS protocol) induced a similar level of LTP $(131.8 \pm 4.5$ vs $136.5 \pm 5.3)$ (Fig. $2 A)$. With an interface chamber, a one-train $100 \mathrm{~Hz}$ protocol induced robust early-phase LTP

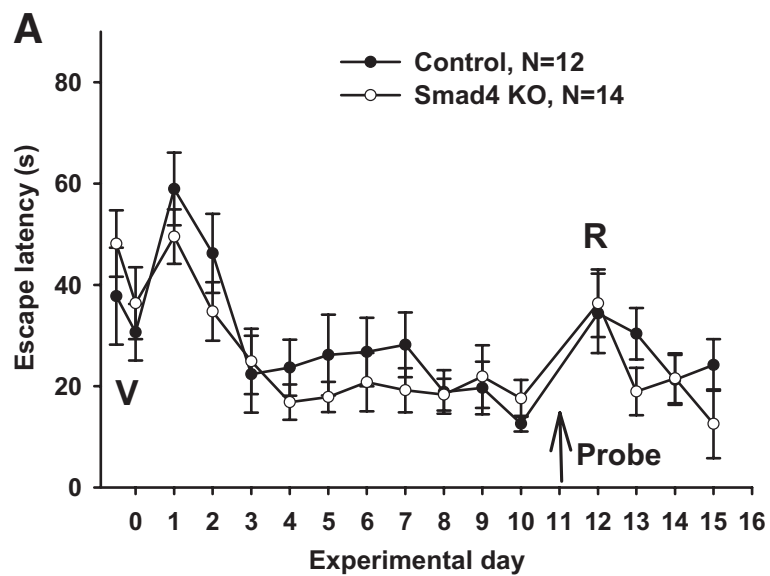

B

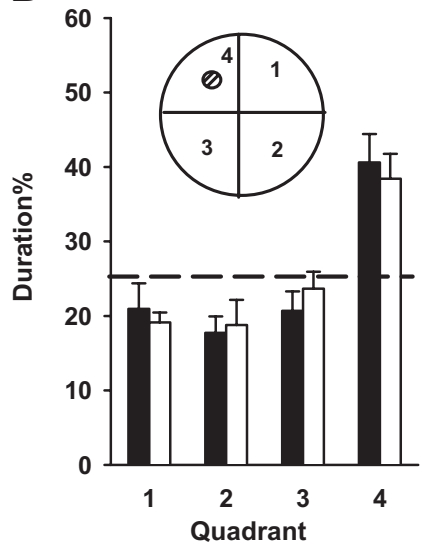

C

Figure 3. Smad4 mutants exhibit normal spatial memory. $\boldsymbol{A}$, In a water maze test, escape latency of both Smad4 KO and control mice were plotted against training day. 0 n day 0 , a visible platform (V) was used; on days 1-15, a hidden platform was used. Probe test was given on day 11 marked with an arrow, when platform was removed from the pool and mice were given $60 \mathrm{~s}$ to explore the pool. Reversal training $(R)$, which the hidden platform was moved to an adjacent quadrant, commenced on day 12 . For $\boldsymbol{A}$, There was no significant difference between the groups in any of the phases of training. $\boldsymbol{B}$, Both Smad4 $\mathrm{KO}$ and control mice showed a similar higher preference for exploring the quadrant in which the platform used to be located. $C$, Both Smad4 $\mathrm{KO}$ and control mice showed no significant difference to the formerly closed arm during a recall test of $Y$ maze.

in both genotypes $(175.2 \pm 11.7$ vs $171.4 \pm 19.2)$ (Fig. $2 B)$, and a four-train $100 \mathrm{~Hz}$ protocol induced sustained late-phase LTP (213.5 \pm 28.0 vs $191.6 \pm 23.2)$ (Fig. $2 C$ ) in both genotypes. Since there is a close relationship between hippocampal LTP and spatial learning, we also tested the performance of $S \operatorname{mad} 4$ mutants in the traditional Morris water maze. Smad4 KO mice performed as well as control mice in locating the hidden platform. Both exhibited similar escape latencies after $10 \mathrm{~d}$ of training and a preference for exploring in the targeted quadrant during a probe test (Fig. $3 A, B)$. In another widely used spatial memory test, the Y maze, Smad4 KO mice and control littermates showed similar frequencies of entry into the novel arm during the free exploration trial (Fig. 3C), consistent with normal spatial memory.

Smad4 KO mice exhibited altered inhibitory use-dependent synaptic modulation, resulting in enhancement of excitatory paired-pulse facilitation

Using field potential recordings from the CA1 region of the hippocampus, we found that Smad4 KO mice showed normal excitatory transmission in the hippocampus compared with controls. 
A

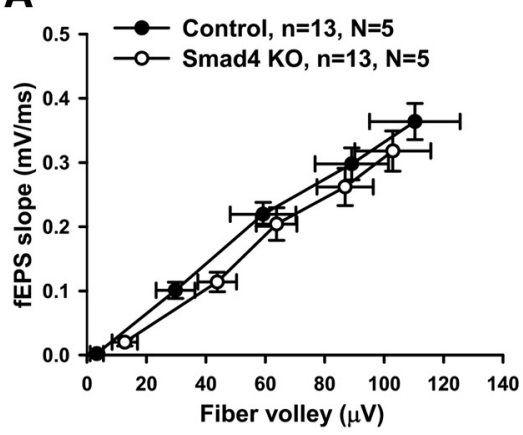

C

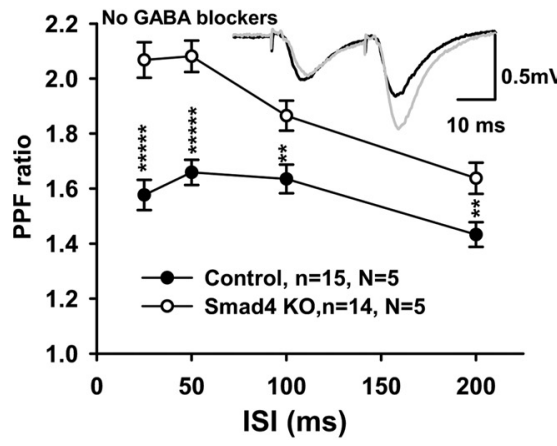

B

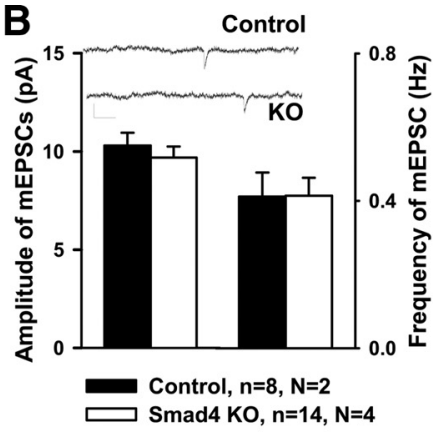

D

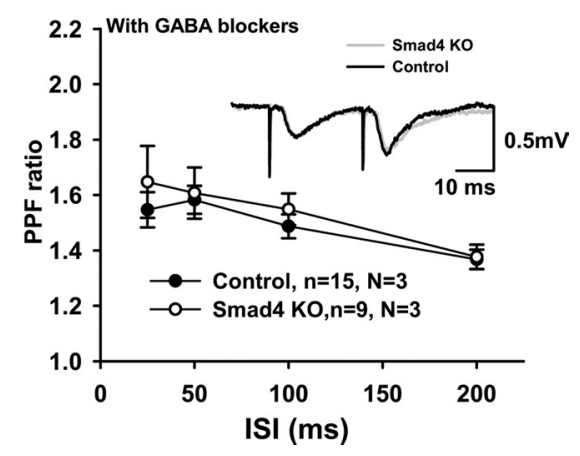

Figure 4. Abnormal excitatory short-term plasticity can be reversed by $\mathrm{GABA}_{\mathrm{A}}$ blocker. $\boldsymbol{A}$, Relationship between the slope of fEPSP and amplitude of presynaptic fiber volley for Smad4 KO and control mice. Data are expressed as mean \pm SEM. Normal input- output curve of Smad4 conditional knock-out mice overlaid on the one of control littermates. $\boldsymbol{B}$, There was no significant difference for mEPSC amplitude and frequency between genotypes. C, PPF was measured as the ratio between the slopes of fEPSPS evoked by the second and first pulses and plotted for several interpulse intervals (ISIs). fEPSPs were evoked with a stimulus that evoked $30 \%$ of the maximal fEPSP with normal ACSF. Values represent mean \pm SEM; ${ }^{* *} p<0.01,{ }^{* * * *} p<0.00001$ (unpaired $t$ test). Representative traces of fEPSPs evoked with $25 \mathrm{~ms} I S I$ are shown in the insets. $\boldsymbol{D}$, Perfusion of the $G_{A B A_{A}}$ antagonist bicuculline $(20 \mu \mathrm{m})$ the $G A B A_{B}$ receptor antagonist CGP54626 (200 nm) began 5 min before the experiment, To avoid epileptic firing of CA3 neurons, a cut was made between CA1 and CA3 cell body after slice preparation. PPF was reversed to normal in Samd4deleted slices.

After normalizing stimulation strength, the input-output curve of the KO group plotted versus the slope of EPSP and the amplitude of presynaptic volley overlapped that of the control group (Fig. 4A). Surprisingly however, paired-pulse facilitation (PPF), a form of short-term plasticity between Schaffer collaterals and CA1 dendrites, was significantly higher in extracellular field recordings from Smad4 KO slices (Fig. 4C). With a series of interpulse intervals, from 25 to $200 \mathrm{~ms}$, Smad4 KO slices showed a dramatic enhancement of the PPF ratio (for example, $1.58 \pm 0.06$ vs $2.07 \pm 0.06$ in $25 \mathrm{~ms}$ ISI, $p<0.00001$ ). This phenotype is in the same direction but much stronger than in $\mathrm{Chrd}^{-/-}$mice, although in that case BMP signaling should be increased while Smad4 loss should produce a decrease in BMP (as well as TGF$\beta$ /activin) signaling. Unexpectedly, both the frequency and amplitude of isolated mEPSCs (miniature EPSCs) were identical in CA1 pyramidal neurons from $\mathrm{KO}$ mice and control littermates with perfusion of GABA blockers (for amplitude, $10.30 \pm 0.65 \mathrm{vs}$ $9.69 \pm 0.57 \mathrm{pA}$; for frequency, $0.41 \pm 0.07$ vs $0.41 \pm 0.05 \mathrm{~Hz}$ ) (Fig. $4 B$ ). These results also distinguish Smad4 $\mathrm{KO}$ from $\mathrm{Chrd}^{-1-}$ mice and also from the case of acute BMP perfusion on wild-type hippocampal slices, both of which exhibit increased glutamergic vesicle release (Sun et al., 2007). Since glutamergic vesicle release is normal in $\mathrm{Smad} 4 \mathrm{KO}$, it strongly suggests that the enhanced field PPF might reflect the alterations in GABAergic transmission. Consistent with this view, we found that when the connection between CA3 and CA1 was cut and GABA blockers

(20 $\mu \mathrm{m}$ bicuculline and $200 \mathrm{~nm}$ CGP) were perfused during field recordings, the enhancement of PPF from Smad4 KO slices was restored to control levels (Fig. 4D), and there was no change in PPF ratio in control slices. These results revealed a defect of GABA transmission in the hippocampus of Smad4-deficient mice.

To further examine this issue, $\mathrm{GABA}_{\mathrm{A}}$ currents were isolated pharmacologically and $\mathrm{GABA}_{\mathrm{A}}$ synaptic strength, and modulation were tested with patch-clamp recordings. Both amplitude and frequency of miniature IPSCs (mIPSCs) recorded in Smad4-null neurons in the CA1 region were similar to those recorded in control littermates $(16.88 \pm 1.37$ vs $19.17 \pm 1.13$ pA; $3.89 \pm 0.45$ vs $3.55 \pm 0.32 \mathrm{~Hz}$ ) (Fig. $5 A, B)$. However, we did find a subtle but significant increase in the decay constant of slow recovery state with a biexponential fit (control, $23.12 \pm 1.28$ vs KO, $29.73 \pm$ 1.92, $p<0.01$ ) (Fig. 5C). The change of $\mathrm{GABA}_{\mathrm{A}}$ channel kinetics could be responsible for the alteration of $\mathrm{GABA}_{\mathrm{A}}$ synaptic transmission.

We next investigated synaptic strength by measuring input-output curves of evoked inhibitory synaptic currents in the CA1 stratum radiatum of $\mathrm{Smad} 4 \mathrm{KO}$ mice and their control littermates. The normalized curves did not diverge significantly from each other (Fig. 5D), supporting the view that basal $\mathrm{GABA}_{\mathrm{A}}$ transmission is normal in Smad4 KO mice. To test the correlation between excitatory and inhibitory short-term plasticity inside the CA1 region, we selected a stimulus intensity that evoked $30 \%$ of maximal dendritic IPSC amplitude and tested short-term plasticity at $\mathrm{GABA}_{\mathrm{A}}$ synapses. Smad4-deficient mice showed an obvious PPD with ISI over a time interval of 25-200 ms. For example, with an ISI of $25 \mathrm{~ms}$, the PPD ratio in Smad4 KO slices was $0.64 \pm 0.06$, compared with $0.83 \pm 0.06$ in control slices $(p<0.05)$. Since

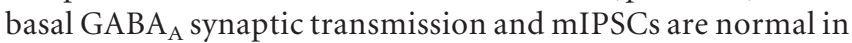
Smad4 KO mice, also the $\mathrm{GABA}_{\mathrm{A}}$ transcriptomes of CA1 neurons from Smad4 KO and control hippocampi were identical (supplemental Fig. 5, available at www.jneurosci.org as supplemental material), a possible explanation for the significant change of PPD in mutant mice is that Smad4-mediated transcription is important for mediating $\mathrm{GABA}_{\mathrm{A}}$ receptor trafficking during use-dependent modulation (Bannai et al., 2009).

\section{Hippocampal Smad4 is critical for control of locomotion}

While conditional loss of Smad4 in the hippocampus did not appear to alter spatial learning and memory, Smad4 KO mice showed altered behaviors when placed in a novel environment. $\mathrm{KO}$ mice showed enhanced overall horizontal locomotion with less habituation in an open field test (Fig. 6). There was no change in the number of times or the speed at which mutant mice crossed the center area compared with control littermates during the 15 min test (Fig. 6A) and they also sniffed a novel object with similar frequency to controls (Fig. 6A). However, the average locomotor speed of Smad4 KO mice was higher than littermates during the 
$15 \mathrm{~min}$ test $(66.45 \pm 3.47 \mathrm{~mm} / \mathrm{s}$ vs $53.94 \pm$ $3.66 \mathrm{~mm} / \mathrm{s}, p<0.05$ ) (Fig. $6 A$ ). This appears to result from reduced habituation, since control mice showed less and less movement during continuous 5 min periods, likely as a result of becoming familiar with the new environment, whereas Smad4 KO mice continued to be hyperactive throughout of the experiment $(62.99 \pm 5.51 \mathrm{~mm} / \mathrm{s}$ vs $50.62 \pm 2.75 \mathrm{~mm} / \mathrm{s}$ during the last $5 \mathrm{~min}$ of the test period, $p<0.05$ ) (Fig. 6B). This may indicate that mutant mice fail to habituate to a novel environment or are abnormally anxious in response to a change in the environment.

To address this issue further, we applied a high-throughput behavioral screening paradigm with an automatic behavior recognition system (Steele et al., 2007) to detect changes in a range of spontaneous behaviors in response to environmental stressors (Fig. 7). We analyzed the first hour of new homecage behavior (NHB) and $12 \mathrm{~h}$ of homecage behavior $(\mathrm{HB})$ on the second experimental day. Both $\mathrm{NHB}$ and $\mathrm{HB}$ were acquired in a single light cycle (Fig. $7 A$, experimental strategy). Generally, mice are highly active upon being transferred to a new homecage containing new bedding, food, and drink. During the first hour in new cages, they do not sleep and continue to explore the new environment, even during the light cycle. The walking distance for control mice increased $>30$ fold $(1.7 \pm 0.4 \mathrm{~m}$ versus $59.0 \pm 5.4 \mathrm{~m})$ (Fig. $7 B$ ) compared with their activity inside familiar homecages. Interestingly, Smad4 KO mice showed impaired NHB. Specifically, grooming behavior was significantly inhibited in control mice, but not in Smad4 KO mice (Fig. 7C). In comparison with $\mathrm{NHB}$, inside a familiar homecage, Smad4 KO mice still showed increased basal activity in their familiar homecages during the light cycle, reflected by a twofold longer walking distance compared with controls (Fig. 7B).

As homecage and open field tests revealed hyperactivity and excessive grooming by Smad4 $\mathrm{KO}$ mice in response to novel environments, we wondered whether this behavioral phenotype might be linked to an increase or decrease in anxiety. The elevated plus maze is the most widely used test for anxiety-like behavior in rodents. This test is dependent on the instinctive conflict between exploration of novel areas and avoidance of their aversive features (Walf and Frye, 2007). In this test, Smad4 KO mice showed the same preference for closed arms, and numbers and duration of arm entries did not differ be-

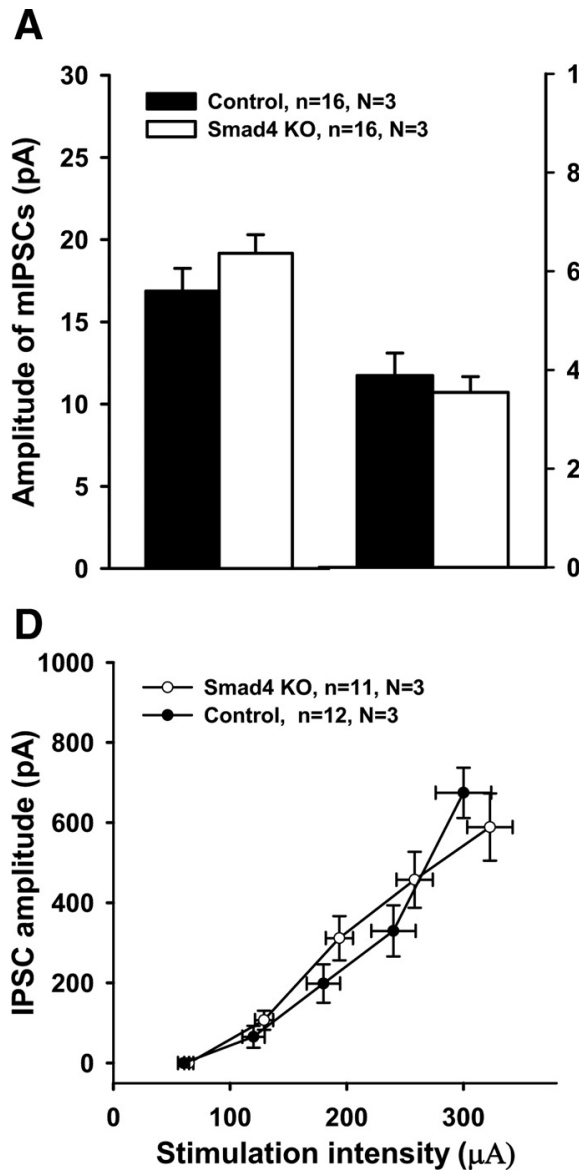

B

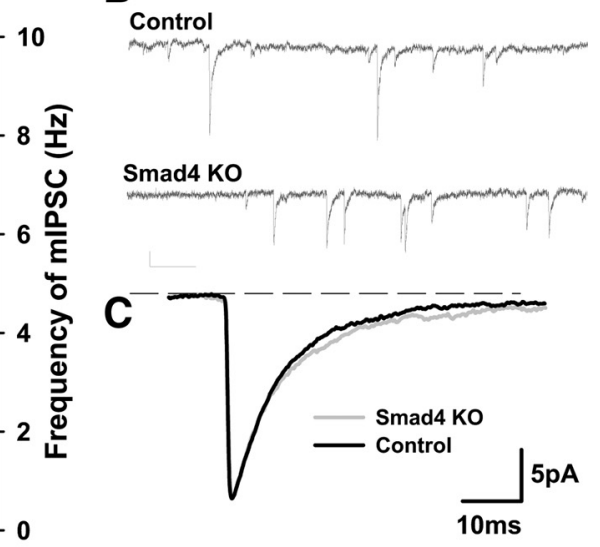

E

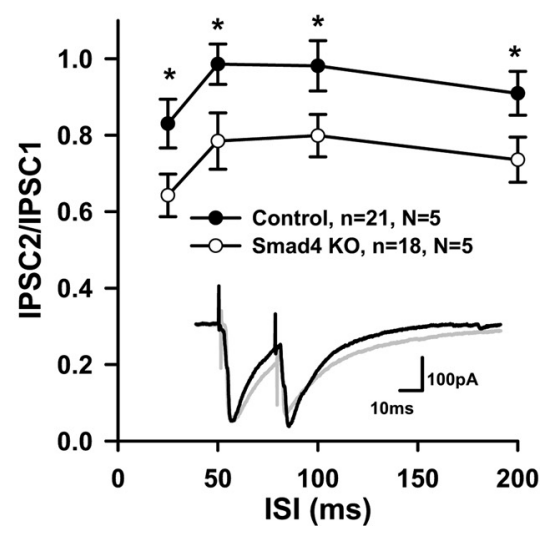

Figure 5. Smad4 mutants showed impaired modulation of inhibitory transmission in CA1. $\boldsymbol{A}$, There was no significant difference for mIPSC amplitude and frequency between genotypes. $\boldsymbol{B}$, Representative sweeps from two groups. $\boldsymbol{C}, A$ subtle but significant higher decay constant $\tau 2$ from Samd 4 KO cells. D. The IPSC input- output curve evoked from the striatum radiatum in Smad4 KO cells was normal. $\boldsymbol{E}$, Significant PPD was recorded from Smad4 KO cells (for each ISI, ${ }^{*} p<0.05$ ).

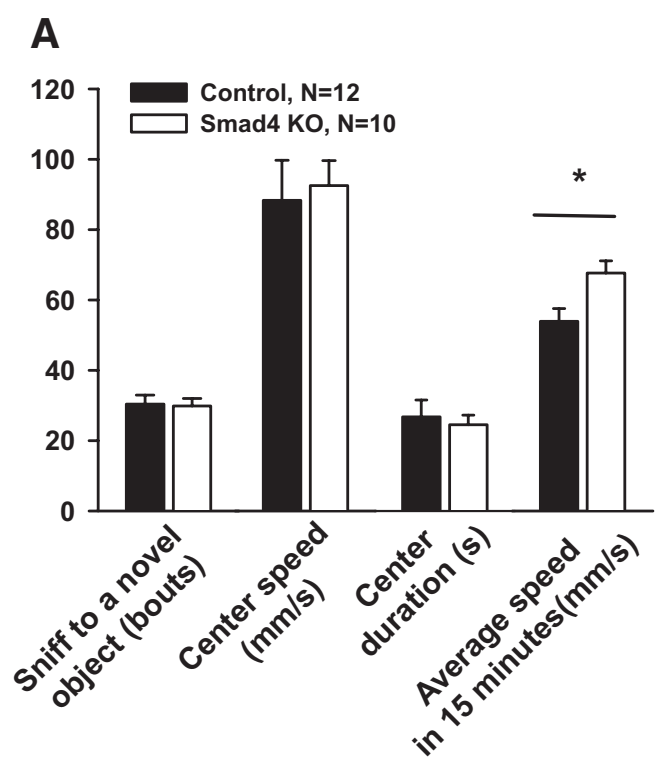

B

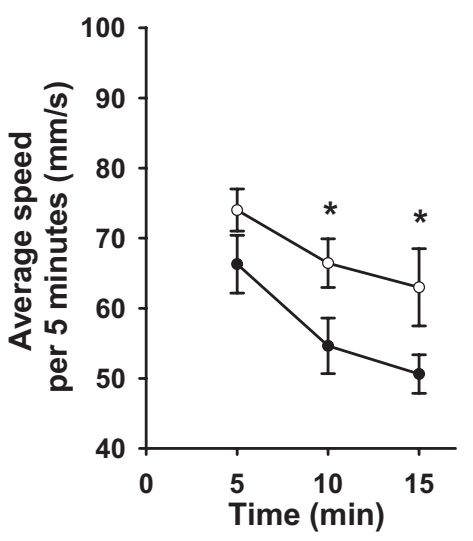

Figure 6. Smad4 mutants showed hyperactivity and less adaptive response in open field test. $\boldsymbol{A}$, Smad4 K0 mice showed no difference in sniffing onto a novel object; no difference in locomotor speed in the central quadrant compared with control mice; no significant difference from control mice in the time they spend in the center, but Smad4 K0 mice ran faster during the 15 min test in an open field. $\boldsymbol{B}$, Smad4 KO mice showed less habituation of locomotor activity in open field test. ${ }^{*} p<0.05$. 
A
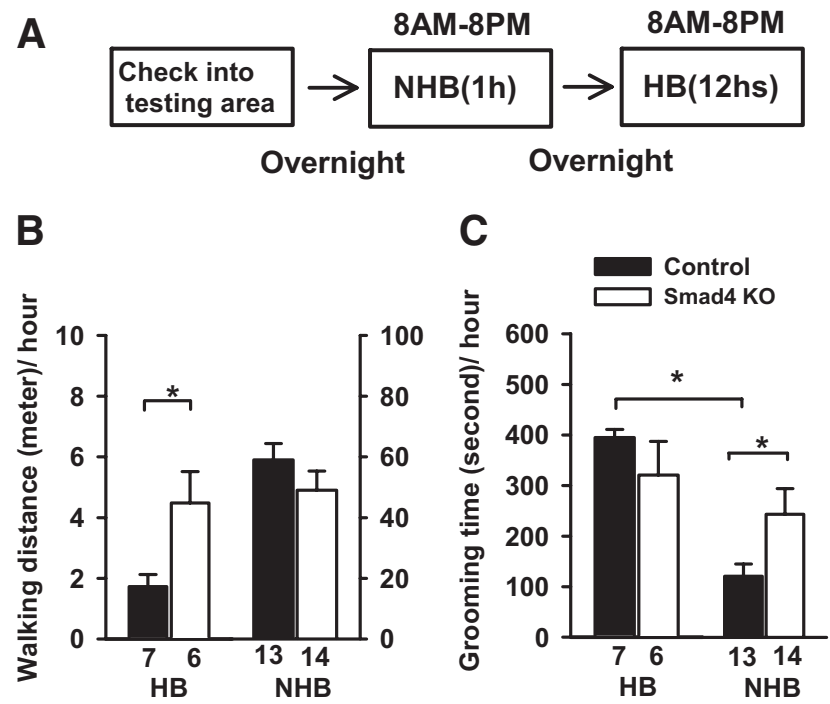

Figure 7. Smad4 K0 mice showed more grooming in new homecages. $A$, The flow chart describes the experimental strategy of homecage behavior; both NHB and HB were acquired during light cycle. $\boldsymbol{B}, \mathrm{Smad} 4 \mathrm{KO}$ mice showed hyperactivity in their homecages, but not in new homecages. C, Smad4 K0 mice showed more grooming in new homecages. ${ }^{*} p<0.05$.

tween two genotypes (supplemental Fig. 4, available at www. jneurosci.org as supplemental material). In terms of ethological measures, Smad4 KO mice also showed no significant difference of head dips in the center or open arms and in risk-assessment behavior, such as adopting a stretch-attend posture.

\section{Deficit of PPI in Smad4 KO mice}

Abnormal paired-pulse facilitation in the hippocampus may lead to disturbances in information-processing. Since prepulse inhibition (PPI) of the startle reflex is a powerful research paradigm for studying neural control in vivo, involving hippocampal integration (Swerdlow et al., 2008), we examined this behavioral index in Smad4 mutants. The magnitude of the startle reflex itself was measured first to exclude the possibility of deafness due to Smad4 removal or early aging. Smad4 mice showed normal startle reflex amplitude upon acoustic stimulation in comparison with control mice (1.69 \pm 0.26 vs $1.94 \pm 0.19$ units). However, we observed a clear trend of decreasing PPI at each sound-pressure level in Smad4-null mutants, with significantly less PPI at the $77 \mathrm{~dB}$ level $(p<$ 0.003 ) (Fig. 8). Along with the behavioral phenotypes of hyperactivity and overgrooming, the deficit of PPI in Smad4 KO mice hints at a disruption of hippocampal network activity, resulting in abnormal behavior.

\section{Self-regulation of TGF- $\beta$ signaling by Smad 4}

To address the issue of how TGF- $\beta$ signaling might alter hippocampal network activity, we initiated a search for potential downstream target genes. Since homeostatic feedback is likely to be an important mechanism that controls network activity, we used a TGF- $\beta$ pathway-specific RT-PCR array which included 84 genes of interest and covered the basic components and regulators of the TGF- $\beta$ signaling pathway (see Materials and Methods). The transcription of three genes emerged as being altered at $>2$-fold control levels with $p<0.05$. These "hits" were Smad4, follistatin (FST), and GDF6. We then validated these changes by quantitative PCR on hippocampal tissue from Smad4 KO and control mice. This study revealed that the most significant change

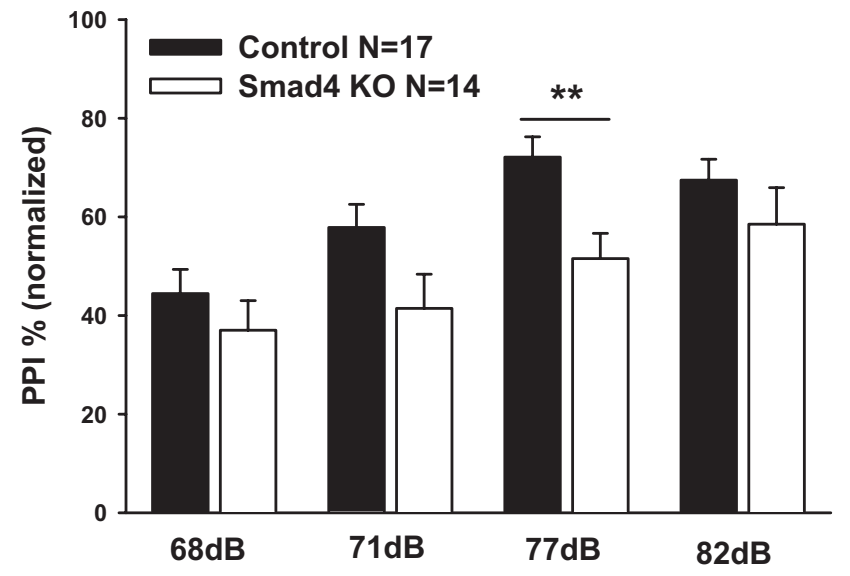

Figure 8. Deficits in PPI in Smad4 K0 mice. Smad4 KO mice showed significantly reduced PPI to a $77 \mathrm{~dB}$ prepulse $\left({ }^{* *} p<0.01\right)$ and a clear trend of a decrease cross each prepulse level.

was upregulation of $f_{s t}$ (Fig. 9A), an extracellular antagonist that binds both activin and BMP ligands. Both exon 3 and exon 6 of $f_{s t}$ are increased in Smad4 KO hippocampi, suggesting that all the RNA splicing isoforms of follistatin (Sugino et al., 1993; Kimura et al., 2010) are upregulated in Smad4 KO hippocampi. We did not detect significant changes in other extracellular TGF- $\beta$ inhibitors such as $f s t l 1, c h r d$, and nog in either the TGF- $\beta$ pathway array or QPCR assays. To examine whether the increase of $f_{s t} \mathrm{mRNA}$ translated into excessive follistatin protein, we performed Western blotting of hippocampal total proteins and found a $>2$-fold increase in FST levels (Fig. 9B). As follistatin is an inhibitor for both BMP and activin/TGF- $\beta$ branches, we determined whether the follistatin overexpression significantly altered phosphorylation of either Smad2 (activin/TGF- $\beta$ branch) or Smad1/5/8 (BMP branch) in Smad4 KO mice. We found that Smad2 phosphorylation was reduced by $\sim 40 \%(p=0.003)$, while pSmad1/5/8 levels were not significantly altered (Fig. 9C). These observations suggest that in the hippocampus, Smad4 negatively regulates follistatin, which in turn appears to primarily inhibit the canonical activin/TGF- $\beta$ signaling branch and not the BMP branch.

\section{Discussion}

The hippocampus is an important structure not only for encoding information and retrieving memory but also for contributing to the integration of multimodal environmental cues. Currently, the neural networks and molecular mechanisms that regulate this integrative function within the hippocampus are unknown. Our data are the first to suggest that the TGF- $\beta$ signaling pathway modulates the hippocampusdependent response to novel environments and integration of multiple sensory inputs.

In Drosophila, the Smad4 homolog Medea has been found to control synaptic growth and synaptic transmission in NMJ (McCabe et al., 2004). Given the expression of Smad4 in adult mouse hippocampus (Fig. 1) [Allen Brain Atlas (http:// mouse.brain-map.og)] and previous studies of TGF- $\beta$ signaling in hippocampal plasticity (Müller et al., 2006; Fukushima et al., 2007; Sun et al., 2007), we hypothesized that Smad4-mediated canonical TGF- $\beta$ signaling would regulate synaptic physiology and related behavior in vivo. Even though a previous knock-out study showed normal neuronal plasticity in the dentate gyrus (Zhou et al., 2003), we reasoned that CA1 LTP and spatial learning are better tools to examine postnatal function of Smad4 in the 
hippocampus. Contrary to our expectation, we found normal spine numbers, glutamergic transmission, LTP, and spatial learning in Smad4 KO mice (Fig. 1). However, Smad4 KO mice showed a dramatically higher excitatory PPF and increase of PPD mediated by $\mathrm{GABA}_{\mathrm{A}}$ receptors in the apical dendritic area of CA1 pyramidal neurons. Through automated ethological assays, we detected hyperactive and overgrooming behavior in Smad4 mutants that could not be explained by a cerebellar defect since the deletion of Smad4 is primarily limited to the hippocampus.

\section{Canonical versus noncanonical}

TGF- $\beta$ pathway signaling in hippocampal function

Previously, we found that chordin knockout mice, an animal model for a gain of function in BMP signaling, exhibit upregulation of excitatory transmission and improved water maze learning (Sun et al., 2007). At the same time, chordin-null mice also showed less exploratory behavior and more anxiety-like behavior in a novel environment. We speculated that the altered excitatory transmission was likely the result of changes in noncanonical, Smad-independent signaling since perfusion of BMPs onto slices leads to rapid alterations in transmission that are inconsistent with the time required for a transcriptional response. The fact that we see no changes in the water maze performance of Smad 4 hippocampal knock-out mice also suggests that the learning enhancement seen in Chrd ${ }^{-1-}$ mice is noncanonically based. This conclusion must be tempered by the observation that loss of Smad4 may not eliminate all canonical signaling (Chu et al., 2004). Interestingly, Smad4-dependent signaling is critical for adult neurogenesis (Colak et al., 2008) and infusion of Noggin intraventrically can affect hippocampal-dependent learning in mouse by regulation of adult stem cells in dentate gyrus (Gobeske et al., 2009). The TGF- $\beta$ signaling pathway may play versatile roles in mature neurons and newborn neurons in different contexts.

Recently, several independent studies indicate that the activin pathway modulates anxiety and depression responses in mice (Dow et al., 2005; Zheng et al., 2009). Inactivation of activin receptor in the forebrain enhanced both $G_{A B A}$ and $G_{A B A}$ currents, but whether this requires canonical signaling was not tested. In contrast, in cultured hippocampal neurons, addition of activin results in spine contact and NMDA receptor changes through protein synthesis-independent (noncanonical) phosphorylation of actin filaments and postsynaptic scaffold proteins (Shoji-Kasai et al., 2007; Kurisaki et al., 2008). Our results suggest that Smad4 regulates $\mathrm{GABA}_{\mathrm{A}}$ transmission; however, since Smad4 represents a point of convergence between TGF- $\beta$ /activin and BMP signaling pathways, it is not clear which set of ligands might be involved in this response.

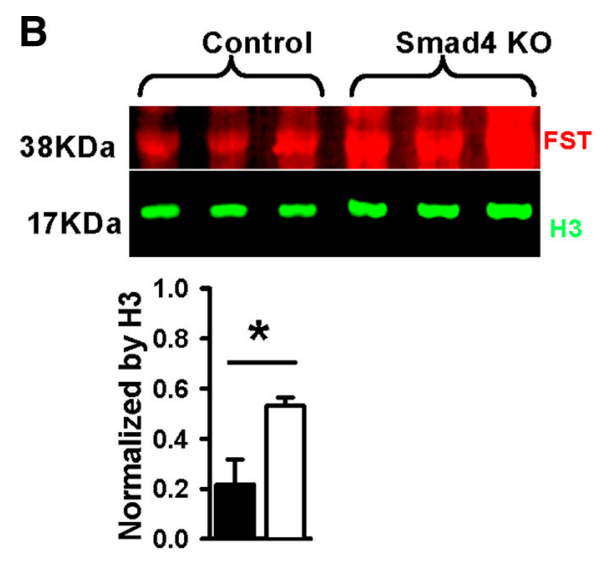

Control, $\mathrm{N}=4$ Smad4 KO, N=5

Control, $\mathrm{N}=3$

Smad4 KO, $\mathrm{N}=3$

Figure 9. Gene transcriptions after Smad4 deletion in the hippocampus. A, QPCR showed significantly increased upreguRight, Western blot double staining with anti-pSmad1/5/8 or pSmad2 antibodies with GAPDH as loading control. Left, Quantification of Western staining shows significant lower intensity of the $\mathrm{pS}$ mad2 band in normalizing with GAPDH, but pSmad1/5/8 was not affected significantly. ${ }^{*} p<0.05$.

The canonical versus noncanonical issue is even more complex when we consider our finding that loss of Smad 4 leads to upregulation of follistatin, an extracellular inhibitor of both BMPs and activin ligands (Phillips, 2000). One might have expected that if a simple homeostatic mechanism operates in the hippocampus to maintain a balance in TGF- $\beta$ signaling, that loss of Smad 4 might lead to upregulation of ligand expression or loss of inhibitor expression in an attempt to restore Smad signaling to normal levels. However, what we observe is very little change in ligand expression (supplemental Table 2, available at www. jneurosci.org as supplemental material) and a substantial increase in the expression of an inhibitor, which might be expected to further exacerbate the problem of low Smad signaling. Moreover, we found follistatin selectively suppressed activin/TGF- $\beta$ signaling in mouse hippocampus. It has been shown that TGF- $\beta$ family signaling regulates other family members' transcript levels by mechanisms of synexpression (Grotewold et al., 2001), autoregulation (Beites et al., 2009), and feedback (Moustakas and Heldin, 2009). Thus, perturbation in the expression of one component often results in transcriptional misregulation of other components including secreted inhibitors. We suggest that follistatin expression is increased in an attempt to turn down 
activin/TGF- $\beta$ signaling and leaves BMP signaling pathway untouched. Since BMP signaling is unaffected, the results further suggest that the complement of BMP ligands expressed in the hippocampus have, in aggregate, a lower affinity for follistatin than do the activin ligands, which is consistent with previous biophysical data demonstrating that the binding affinities of follistatin to BMPs 2, 4, and 7 range from 5 to $80 \mathrm{~nm}$ (Amthor et al., 2002), whereas the binding affinity of follistatin to activin $A$ is in the 40 pm range (Hashimoto et al., 2000).

\section{Short-term synaptic plasticity and behavioral significance}

Synaptic computation appears to involve multiple mechanisms of synaptic plasticity, especially short-term plasticity (Abbott and Regehr, 2004). The summation of both glutamergic and GABAergic inputs on apical dendrites of pyramidal neurons could amplify the computational capacity of a single neuron and stabilize hippocampal circuits. As paired stimulation produced less inhibition in Smad4 KO dendrites, the dendritic excitability was upregulated transiently and PPF enhanced. From our observations, the significant PPD in Smad4-null neurons is likely the source of destabilization of hippocampal circuits, leading to behavioral defects in vivo.

Significant PPD of $\mathrm{GABA}_{\mathrm{A}}$ currents in Smad4 mutants could derive from three sources. The first possibility is low transmitter release from presynaptic termini. This is least likely, because GABAergic presynaptic termini should be intact, as the CaMKII promoter is active only in pyramidal cells and mIPSC frequency is normal. The second possibility is $\mathrm{GABA}_{\mathrm{A}}$ receptor desensitization. We detected a subtle increase in the mIPSC decay constant in Smad4 knock-out neurons, which could reflect different subunit localization on the dendrites. Thus, different $\mathrm{GABA}_{\mathrm{A}}$ subunits have different decay times, with $\alpha 1$ faster than $\alpha 2$ and $\alpha 3$ (Goldstein et al., 2002). $\alpha$ 5-null mice show increases in PPF (Collinson et al., 2002). Different subunits of $\mathrm{GABA}_{\mathrm{A}}$ could contribute to PPD after short interpulse intervals, but not likely after 200 ms, which is much longer than the decay period of the $\mathrm{GABA}_{\mathrm{A}}$ current. Our homemade GABA $\mathrm{APCR}$ array (supplemental Fig. 5 and supplemental Table 2, available at www.jneurosci.org as supplemental material) did not detect significant alterations in the mRNA composition of any subunits, thereby arguing against the possibility of transcriptional control of $\mathrm{GABA}_{\mathrm{A}}$ subunits directly by Smad4-mediated TGF- $\beta$ signaling. A third possibility is that of $\mathrm{GABA}_{\mathrm{A}}$ receptor redistribution, which depends on fast exchanges of desensitized receptors for naive functional ones. This hypothesis has been tested on AMPA ionotropic receptors (Heine et al., 2008) and most likely occurs in $\mathrm{GABA}_{\mathrm{A}}$ receptors as well (Jacob et al., 2008). Since the $\mathrm{GABA}_{\mathrm{A}}$-related transcriptome profiling in Smad4 KO hippocampi did not provide evidence that canonical TGF- $\beta$ signaling regulates components of $\mathrm{GABA}_{\mathrm{A}}$ at the transcription level, we infer that the regulation occurs at the level of translation or trafficking of these receptors.

$\mathrm{GABA}_{\mathrm{A}}$ currents are the most prevalent form of neurotransmitter-mediated inhibitory activity in the brain and play an important role in physiological processes and pathophysiological conditions (Fritschy and Brünig, 2003), such as homeostasis of neural circuits sedation, sleep induction, anxiety, seizures, and cognition. Hyperactivity in Smad4 KO mice was observed across several assays. In an open field, these mutants showed significant increases of overall locomotor speed and less habituation. Over $12 \mathrm{~h}$ of observation in their homecage, they showed a twofold increase in distance traveled. It is known that disinhibition of the dorsal hippocampus by blockade of $\mathrm{GABA}_{\mathrm{A}}$ transmission increases locomotor and anxiety-like behavior in the open field test
(Bast et al., 2001). Also, Smad4 KO mice showed stereotypic grooming in new homecages. The stress associated with introduction to a new environment significantly inhibited grooming behavior in control mice, but not in Smad4-null mice, which groomed more than control mice in new homecages. Further classification of the microstructure of stress-induced grooming will help us determine whether overgrooming is a marker for anxiety, schizophrenia, or other pathophysiological conditions (Kalueff et al., 2007).

Extensive studies in humans and animals have demonstrated PPI as one of the best candidate endophenotypes for psychiatric disorders, especially for schizophrenia (Gottesman and Gould, 2003). Although its neurochemical and anatomical substrates have been analyzed (Geyer et al., 2002; Swerdlow et al., 2008), the mechanism of PPI is still poorly understood at the synaptic level. While both presynaptic and postsynaptic mechanisms may be involved (Frost et al., 2003), there is no evidence directly implicating short-term synaptic plasticity in the expression of PPI. It is intriguing to note the parallel deficits in hippocampal abnormal short-term plasticity and prepulse inhibition of the startle reflex in Smad4 KO mice and to speculate that these two phenomena may be causally related. Nevertheless, it may not be coincidental that short-term plasticity (PPF or PPD) and PPI are observed over a similar range of interstimulus intervals, and the possibility that short-term synaptic plasticity in the mouse hippocampus regulates PPI in whole animal is certainly consistent with our data. Eventually, measuring PPI and short-term plasticity simultaneously in vivo in circuits that mediate and modulate the phenomenon of PPI could test this hypothesis.

Recently, disruptions in several other growth factor signaling pathways, such as BDNF and ERK signaling, have also been associated with hyperactivity and deficits in PPI. Mice with a conditional knock-out of the TrkB receptor in the forebrain showed hyperactive instead of depression-like behavior (Zorner et al., $2003)$. Overexpression of glycogen synthase kinase $3 \beta$ (GSK-3 $\beta$ ) in mice showed both increased hippocampal BDNF expression and behavioral hyperactivity (Prickaerts et al., 2006).

In conclusion, our studies strongly suggest that Smad4mediated canonical TGF- $\beta$ signaling is dispensable for hippocampal LTP or spatial learning, but it is critical for local dendritic homeostasis in CA1. It is clear that Smad4 deletion affects locomotor activity and PPI via $\mathrm{GABA}_{\mathrm{A}}$ use-dependent modulation. In the future, further differentiation of canonical and noncanonical pathways of TGF- $\beta$ signaling will help clarify how TGF- $\beta$ ligands modulate the normal mood state.

\section{References}

Abbott LF, RegehrWG (2004) Synaptic computation. Nature 431:796-803. Ageta H, Murayama A, Migishima R, Kida S, Tsuchida K, Yokoyama M, Inokuchi K (2008) Activin in the brain modulates anxiety-related behavior and adult neurogenesis. PLoS One 3:e1869.

Amthor H, Christ B, Rashid-Doubell F, Kemp CF, Lang E, Patel K (2002) Follistatin regulates bone morphogenetic protein-7 (BMP-7) activity to stimulate embryonic muscle growth. Dev Biol 243:115-127.

Baines RA (2004) Synaptic strengthening mediated by bone morphogenetic protein-dependent retrograde signaling in the Drosophila CNS. J Neurosci 24:6904-6911.

Bannai H, Lévi S, Schweizer C, Inoue T, Launey T, Racine V, Sibarita JB, Mikoshiba K, Triller A (2009) Activity-dependent tuning of inhibitory neurotransmission based on GABAAR diffusion dynamics. Neuron 62:670-682.

Bast T, Zhang WN, Feldon J (2001) Hyperactivity, decreased startle reactivity, and disrupted prepulse inhibition following disinhibition of the rat ventral hippocampus by the GABA(A) receptor antagonist picrotoxin. Psychopharmacology (Berl) 156:225-233. 
Beites CL, Hollenbeck PL, Kim J, Lovell-Badge R, Lander AD, Calof AL (2009) Follistatin modulates a BMP autoregulatory loop to control the size and patterning of sensory domains in the developing tongue. Development 136:2187-2197.

Benes FM, Lim B, Matzilevich D, Walsh JP, Subburaju S, Minns M (2007) Regulation of the GABA cell phenotype in hippocampus of schizophrenics and bipolars. Proc Natl Acad Sci U S A 104:10164-10169.

Chin J, Angers A, Cleary LJ, Eskin A, Byrne JH (2002) Transforming growth factor beta1 alters synapsin distribution and modulates synaptic depression in Aplysia. J Neurosci 22:RC220.

Chu GC, Dunn NR, Anderson DC, Oxburgh L, Robertson EJ (2004) Differential requirements for Smad4 in TGFbeta-dependent patterning of the early mouse embryo. Development 131:3501-3512.

Colak D, Mori T, Brill MS, Pfeifer A, Falk S, Deng C, Monteiro R, Mummery C, Sommer L, Götz M (2008) Adult neurogenesis requires Smad4mediated bone morphogenic protein signaling in stem cells. J Neurosci 28:434-446.

Collinson N, Kuenzi FM, Jarolimek W, Maubach KA, Cothliff R, Sur C, Smith A, Otu FM, Howell O, Atack JR, McKernan RM, Seabrook GR, Dawson GR, Whiting PJ, Rosahl TW (2002) Enhanced learning and memory and altered GABAergic synaptic transmission in mice lacking the $\alpha 5$ subunit of the $\mathrm{GABA}_{\mathrm{A}}$ receptor. J Neurosci 22:5572-5580.

Dow AL, Russell DS, Duman RS (2005) Regulation of activin mRNA and Smad2 phosphorylation by antidepressant treatment in the rat brain: effects in behavioral models. J Neurosci 25:4908-4916.

Dragatsis I, Zeitlin S (2000) CaMKIIalpha-Cre transgene expression and recombination patterns in the mouse brain. Genesis 26:133-135.

Eaton BA, Davis GW (2005) LIM kinasel controls synaptic stability downstream of the type II BMP receptor. Neuron 47:695-708.

Fritschy JM, Brünig I (2003) Formation and plasticity of GABAergic synapses: physiological mechanisms and pathophysiological implications. Pharmacol Ther 98:299-323.

Frost WN, Tian LM, Hoppe TA, Mongeluzi DL, Wang J (2003) A cellular mechanism for prepulse inhibition. Neuron 40:991-1001.

Fukushima T, Liu RY, Byrne JH (2007) Transforming growth factor-beta2 modulates synaptic efficacy and plasticity and induces phosphorylation of CREB in hippocampal neurons. Hippocampus 17:5-9.

Geyer MA, McIlwain KL, Paylor R (2002) Mouse genetic models for prepulse inhibition: an early review. Mol Psychiatry 7:1039-1053.

Gobeske KT, Das S, Bonaguidi MA, Weiss C, Radulovic J, Disterhoft JF, Kessler JA (2009) BMP signaling mediates effects of exercise on hippocampal neurogenesis and cognition in mice. PLoS One 4:e7506.

Goldstein PA, Elsen FP, Ying SW, Ferguson C, Homanics GE, Harrison NL (2002) Prolongation of hippocampal miniature inhibitory postsynaptic currents in mice lacking the GABA(A) receptor alphal subunit. J Neurophysiol 88:3208-3217.

Goold CP, Davis GW (2007) The BMP ligand Gbb gates the expression of synaptic homeostasis independent of synaptic growth control. Neuron 56:109-123.

Gottesman II, Gould TD (2003) The endophenotype concept in psychiatry: etymology and strategic intentions. Am J Psychiatry 160:636-645.

Grotewold L, Plum M, Dildrop R, Peters T, Rüther U (2001) Bambi is coexpressed with Bmp-4 during mouse embryogenesis. Mech Dev 100:327-330.

Hashimoto O, Kawasaki N, Tsuchida K, Shimasaki S, Hayakawa T, Sugino H (2000) Difference between follistatin isoforms in the inhibition of activin signalling: activin neutralizing activity of follistatin isoforms is dependent on their affinity for activin. Cell Signal 12:565-571.

Heine M, Groc L, Frischknecht R, Béïque JC, Lounis B, Rumbaugh G, Huganir RL, Cognet L, Choquet D (2008) Surface mobility of postsynaptic AMPARs tunes synaptic transmission. Science 320:201-205.

Jacob TC, Moss SJ, Jurd R (2008) GABA(A) receptor trafficking and its role in the dynamic modulation of neuronal inhibition. Nat Rev Neurosci 9:331-343.

Kalueff AV, Aldridge JW, LaPorte JL, Murphy DL, Tuohimaa P (2007) Analyzing grooming microstructure in neurobehavioral experiments. Nat Protoc 2:2538-2544.

Kimura F, Sidis Y, Bonomi L, Xia Y, Schneyer A (2010) The follistatin-288 isoform alone is sufficient for survival but not for normal fertility in mice. Endocrinology 151:1310-1319.

König HG, Kögel D, Rami A, Prehn JH (2005) TGF-\{beta\}1 activates two distinct type I receptors in neurons: implications for neuronal NF\{kappa\}B signaling. J Cell Biol 168:1077-1086.

Kurisaki A, Inoue I, Kurisaki K, Yamakawa N, Tsuchida K, Sugino H (2008) Activin induces long-lasting $\mathrm{N}$-methyl-D-aspartate receptor activation via scaffolding PDZ protein activin receptor interacting protein 1 . Neuroscience 151:1225-1235.

Law JW, Lee AY, Sun M, Nikonenko AG, Chung SK, Dityatev A, Schachner M, Morellini F (2003) Decreased anxiety, altered place learning, and increased CA1 basal excitatory synaptic transmission in mice with conditional ablation of the neural cell adhesion molecule L1. J Neurosci 23:10419-10432.

Lee-Hoeflich ST, Causing CG, Podkowa M, Zhao X, Wrana JL, Attisano L (2004) Activation of LIMK1 by binding to the BMP receptor, BMPRII, regulates BMP-dependent dendritogenesis. EMBO J 23:4792-4801.

Liu A, Niswander LA (2005) Bone morphogenetic protein signalling and vertebrate nervous system development. Nat Rev Neurosci 6:945-954.

Loeys BL, Chen J, Neptune ER, Judge DP, Podowski M, Holm T, Meyers J, Leitch CC, Katsanis N, Sharifi N, Xu FL, Myers LA, Spevak PJ, Cameron DE, De Backer J, Hellemans J, Chen Y, Davis EC, Webb CL, Kress W, Coucke P, Rifkin DB, De Paepe AM, Dietz HC (2005) A syndrome of altered cardiovascular, craniofacial, neurocognitive and skeletal development caused by mutations in TGFBR1 or TGFBR2. Nat Genet 37: 275-281.

Massagué J (1996) TGFbeta signaling: receptors, transducers, and Mad proteins. Cell 85:947-950.

McCabe BD, Hom S, Aberle H, Fetter RD, Marques G, Haerry TE, Wan H, O'Connor MB, Goodman CS, Haghighi AP (2004) Highwire regulates presynaptic BMP signaling essential for synaptic growth. Neuron 41:891-905.

Moustakas A, Heldin CH (2009) The regulation of TGFbeta signal transduction. Development 136:3699-3714.

Müller MR, Zheng F, Werner S, Alzheimer C (2006) Transgenic mice expressing dominant-negative activin receptor IB in forebrain neurons reveal novel functions of activin at glutamatergic synapses. J Biol Chem 281:29076-29084.

Parker L, Ellis JE, Nguyen MQ, Arora K (2006) The divergent TGF-beta ligand Dawdle utilizes an activin pathway to influence axon guidance in Drosophila. Development 133:4981-4991.

Phillips DJ (2000) Regulation of activin's access to the cell: why is Mother Nature such a control freak? Bioessays 22:689-696.

Prickaerts J, Moechars D, Cryns K, Lenaerts I, van Craenendonck H, Goris I, Daneels G, Bouwknecht JA, Steckler T (2006) Transgenic mice overexpressing glycogen synthase kinase $3 \beta$ : a putative model of hyperactivity and mania. J Neurosci 26:9022-9029.

Serpe M, O'Connor MB (2006) The metalloprotease tolloid-related and its TGF-beta-like substrate Dawdle regulate Drosophila motoneuron axon guidance. Development 133:4969-4979.

Shoji-Kasai Y, Ageta H, Hasegawa Y, Tsuchida K, Sugino H, Inokuchi K (2007) Activin increases the number of synaptic contacts and the length of dendritic spine necks by modulating spinal actin dynamics. J Cell Sci 120:3830-3837.

Steele AD, Jackson WS, King OD, Lindquist S (2007) The power of automated high-resolution behavior analysis revealed by its application to mouse models of Huntington's and prion diseases. Proc Natl Acad Sci U S A 104:1983-1988.

Sugino K, Kurosawa N, Nakamura T, Takio K, Shimasaki S, Ling N, Titani K, Sugino H (1993) Molecular heterogeneity of follistatin, an activinbinding protein. Higher affinity of the carboxyl-terminal truncated forms for heparan sulfate proteoglycans on the ovarian granulosa cell. J Biol Chem 268:15579-15587.

Sun M, Thomas MJ, Herder R, Bofenkamp ML, Selleck SB, O’Connor MB (2007) Presynaptic contributions of chordin to hippocampal plasticity and spatial learning. J Neurosci 27:7740-7750.

Swerdlow NR, Weber M, Qu Y, Light GA, Braff DL (2008) Realistic expectations of prepulse inhibition in translational models for schizophrenia research. Psychopharmacology (Berl) 199:331-388.

Tesseur I, Zou K, Esposito L, Bard F, Berber E, Can JV, Lin AH, Crews L, Tremblay P, Mathews P, Mucke L, Masliah E, Wyss-Coray T (2006) Deficiency in neuronal TGF-beta signaling promotes neurodegeneration and Alzheimer's pathology. J Clin Invest 116:3060-3069.

Ueberham U, Ueberham E, Gruschka H, Arendt T (2006) Altered subcellu- 
lar location of phosphorylated Smads in Alzheimer's disease. Eur J Neurosci 24:2327-2334.

Walf AA, Frye CA (2007) The use of the elevated plus maze as an assay of anxiety-related behavior in rodents. Nat Protoc 2:322-328.

Yang X, Li C, Herrera PL, Deng CX (2002) Generation of Smad4/Dpc4 conditional knock-out mice. Genesis 32:80-81.

Zhang F, Endo S, Cleary LJ, Eskin A, Byrne JH (1997) Role of transforming growth factor-beta in long-term synaptic facilitation in Aplysia. Science 275:1318-1320.

Zheng F, Adelsberger H, Müller MR, Fritschy JM, Werner S, Alzheimer C (2009) Activin tunes GABAergic neurotransmission and modulates anxiety-like behavior. Mol Psychiatry 14:332-346.

Zheng X, Wang J, Haerry TE, Wu AY, Martin J, O’Connor MB, Lee CH,
Lee T (2003) TGF-beta signaling activates steroid hormone receptor expression during neuronal remodeling in the Drosophila brain. Cell 112:303-315.

Zheng X, Zugates CT, Lu Z, Shi L, Bai JM, Lee T (2006) Baboon/dSmad2 TGF-beta signaling is required during late larval stage for development of adult-specific neurons. EMBO J 25:615-627.

Zhou YX, Zhao M, Li D, Shimazu K, Sakata K, Deng CX, Lu B (2003) Cerebellar deficits and hyperactivity in mice lacking Smad4. J Biol Chem 278:42313-42320.

Zorner B, Wolfer DP, Brandis D, Kretz O, Zacher C, Madani R, Grunwald I, Lipp HP, Klein R, Henn FA, Gass P (2003) Forebrain-specific trkBreceptor knockout mice: behaviorally more hyperactive than "depressive." Biol Psychiatry 54:972-982. 